\title{
Differential expression of PD-1 and Tim-3 marks activation versus exhaustion status of $T$ cells in the tumor microenvironment
}

\author{
Jing $\mathrm{Li}^{1^{*}}$, Robert L Ferris ${ }^{2}$ \\ From Society for Immunotherapy of Cancer 29th Annual Meeting \\ National Harbor, MD, USA. 6-9 November 2014
}

Programmed Death 1 (PD-1) and T cell Ig and mucin domain-3 protein (Tim-3) are two immune checkpoint receptors (ICR) highly co-expressed on tumor infiltrating T lymphocytes (TIL). PD-1 has been shown to inhibit $\mathrm{T}$ cell activation and type $1 \mathrm{~T}$ cell responses, while Tim-3 has been proposed as a further marker of exhaustion on TIL $[1,2]$, leading us to investigate the phenotypic and functional characteristics of TIL with differential PD-1 and Tim-3 expression from head and neck cancer (HNC) patients. Our data showed that PD- $1^{+} \mathrm{Tim}-3^{+} \mathrm{CD} 8^{+}$and Foxp3 $3^{-} \mathrm{CD}^{+}$TILs manifested high phosphorylated signal transducers and activators of transcription 1 (p-STAT1) and the associated Th1 transcription factor T-bet, which might correlate with $\mathrm{T}$ cell exhaustion, both at baseline and upon TCR stimulation. Moreover, the sorted PD-1 ${ }^{+} \mathrm{Tim}-3^{+} \mathrm{CD}^{+}$TILs expressed the lowest IFN- $\gamma$ and TNF$\alpha$ transcripts and the least amount of secreted IFN- $\gamma$ upon TCR stimulation, indicating they are the most dysfunctional $\mathrm{T}$ cells in the tumor microenvironment (TME). Among $\mathrm{CD} 4^{+} \mathrm{CD} 25^{\text {lo/- }}$ TIL subsets, PD- ${ }^{\text {hi }}$ Tim- $-3^{-}$cells are more defective in terms of IFN- $\gamma$ expression. Sorted PD$1^{\text {int }}$ Tim $-3^{-} \mathrm{CD}^{+}$and $\mathrm{CD} 4^{+} \mathrm{CD} 25^{\mathrm{lo} /-}$ TILs showed higher TCR-stimulated expression of IFN- $\gamma$ and TNF- $\alpha$ transcripts and secretion of IFN- $\gamma$, suggesting they are the most activated subsets. In addition, sorted PD $-1^{+}$Tim $-3^{+}$ and PD- $1^{\text {hi }}$ Tim- $3^{-}$TIL were less proliferative than other subsets, concomitant with lower expression of phosphorylated S6 (p-S6), while PD- $1^{\text {int }}$ Tim- $3^{-}$, PD-1 ${ }^{-}$Tim- $3^{+}$ and $\mathrm{PD}-1^{-}$Tim- $3^{-}$TIL retained $\mathrm{p}-\mathrm{S} 6$ activation or proliferation, suggesting that high expression of PD-1 on $\mathrm{T}$ cells interferes with TCR or Tim-3 signaling and associated cellular activation status. Taken together,
PD $-1^{+}$Tim $-3^{+}$and PD- $1^{\text {hi }}$ Tim $-3^{-}$TIL are most dysfunctional, while PD- $1^{\text {int }}$ Tim- $3^{-}$TIL are more activated in terms of both Th1 cytokine production and proliferation. These results provide a better understanding of the functional status of TIL subsets and roles of PD-1 and Tim-3 in regulating anti-tumor $\mathrm{T}$ cell response, as targets for cancer immunotherapy.

\section{Authors' details}

${ }^{1}$ Department of Pharmacy, School of Medicine, Tsinghua University, Beijing, China, Pittsburgh, PA, USA. ${ }^{2}$ University of Pittsburgh Cancer Institute, Pittsburgh, PA, USA.

Published: 6 November 2014

References

1. Jin HT, Anderson AC, Tan WG, et al: Cooperation of Tim-3 and PD-1 in CD8 T-cell exhaustion during chronic viral infection. Proceedings of the National Academy of Sciences of the United States of America 2010, 107:14733-8.

2. Fourcade J, Sun Z, Benallaoua M, et al: Upregulation of Tim-3 and PD-1 expression is associated with tumor antigen-specific CD8+ T cell dysfunction in melanoma patients. The Journal of experimental medicine 2010, 207:2175-86.

doi:10.1186/2051-1426-2-S3-P220

Cite this article as: Li and Ferris: Differential expression of PD-1 and Tim-3 marks activation versus exhaustion status of T cells in the tumor microenvironment. Journal for ImmunoTherapy of Cancer 2014 2(Suppl 3): P220. 